\title{
RESEARCH
}

\section{Using Visual Thinking Strategies to Support Pharmacy Student Competency Development to Enable Person-Centered Care}

\author{
Trudi Aspden, PhD, ${ }^{\mathrm{a}}$ John P Egan, PhD, MA, ${ }^{\mathrm{b}}$ Lynne Bye, ${ }^{\mathrm{a}}$ Lynne Petersen, $\mathrm{BEd}^{\mathrm{a}}$ \\ ${ }^{a}$ University of Auckland, School of Pharmacy, Auckland, New Zealand \\ ${ }^{\mathrm{b}}$ University of Auckland, Learning and Teaching Unit, Auckland, New Zealand
}

Corresponding Author: Trudi Aspden, The University of Auckland, School of Pharmacy, Faculty of Medical and Health Sciences, Private Bag 92019, Auckland, New Zealand. Tel: +64(9)3737599. Email: t.aspden@auckland.ac.nz

Submitted February 20, 2021; accepted July 23, 2021; ePublished August 2021

Objective. To evaluate the introduction of ten Visual Thinking Strategy (VTS) sessions into Year 2 of our BPharm programme with the aim of assisting students to develop skills and attitudes required for inclusive practice.

Methods. The evaluation used a cross-sectional study design. All members of the first two successive student cohorts completing multiple VTS sessions were asked to consent for their evaluation responses to be used for research purposes. Each completed a 38-item online reflective questionnaire exploring student perceptions of competency development, transference and session acceptability. Closed-question responses were analysed in Excel to produce descriptive statistics. Free-text responses were categorised and quantified using an inductive approach and manifest content analysis.

Results. The responses of 56\% ( $\mathrm{n}=98 / 147$ ) students were analysed. Students generally believed the sessions had supported the development of the person-centred communication, cultural competence and critical thinking skills surveyed. The minimum level of agreement with an improvement occurring was $74.5 \%$. Free-text responses revealed the perception of additional skill and attitude development. Sixty percent of participants had thought about the VTS questions or used what they had learned in the VTS sessions in other settings. Eighty six percent of students agreed that VTS should remain in the curriculum.

Conclusion. Incorporating regular VTS sessions into Year 2 of the BPharm programme appears to be acceptable to students. Data suggest inclusion of multiple VTS sessions are a valuable addition to health curriculum, offering affective learning experiences which support development and transference of key skills and attitudes relating to provision of inclusive person-centred care.

Keywords: Visual Thinking Strategies, patient-centred care, pharmacy education, affective learning, competencies, transfer of learning

\section{INTRODUCTION}

In Aotearoa New Zealand, as in other parts of the world, health equity is a goal of many health professionals. ${ }^{1-}$ ${ }^{5}$ Consequently, pharmacy services should be provided in a person-centered and inclusive manner as every individual has the right to have their needs understood and receive health services where their wishes are taken into account and their values, and beliefs accommodated. ${ }^{6,7}$ In health care, working inclusively has recently been defined as engaging authentically with people and working effectively in relationships of difference which can involve "ambiguity, contradiction, uncertainty and paradox". ${ }^{8}$ Demographically New Zealand is considered to be both bi-cultural and multicultural. ${ }^{9}$ As such, culturally safe practices are an important element of inclusive practice. ${ }^{10}$ They require health professionals to consider power dynamics and imbalances within therapeutic relationships, patients' rights and selfreflecting on the potential impact of their own culture and biases on their interactions with others. ${ }^{11-14}$ Relatedly, cultural competence in a global context can be grouped into broad domains, of an awareness of own cultural biases and background, knowledge of other cultures, and an ability to respectfully manage the dynamics of difference. . $^{15-18}$ However, supporting undergraduate pharmacy students to develop the skills and attitudes required to practice in such an inclusive manner can be challenging within curricular constraints. Our national registration competence standards ${ }^{19}$, require a sensitive, proactive approach ${ }^{20}$ with a focus on the affective domain of learning. ${ }^{21,22}$

Visual Thinking Strategies (VTS) is a pedagogical method from outside of health originally designed by Abigail Housen and Philip Yenawine to create inclusive discussions fostering a range of person-centered competency development. It uses small group teaching sessions to explore and make sense of creative works using a structured facilitation method. ${ }^{23,24}$ VTS pedagogy is constructivist ${ }^{25}$ and aligns with Bruner's view of problem solving stages in that it involves exploration, extraction of relevant information, simplification and organization of information. ${ }^{26}$ Originally designed to assist children to develop visual literacy and other transferable skills, increasingly VTS has been used in health professional curricula, often as an elective option, for a variety of purposes including improving 
observation skills and tolerance for ambiguity development ${ }^{27}$, and for building listening, analytical and teamwork skills. $^{28}$

In 2016, we piloted a project weaving VTS sessions throughout the entry year clinical and professional skills modules in our revised integrated Bachelor of Pharmacy (BPharm) curriculum at the University of Auckland. These modules enable students to develop knowledge and skills needed for competent pharmacy practice and include aspects of professionalism, clinical communication, and human behavior.

These VTS sessions were designed to support development of students' transferable competencies and attitudes relating to inclusive person-centered practices including, communication, cultural safety, critical thinking and reflection. These aspects are important globally for inclusive practice as they facilitate relationship building and meeting the needs of diverse health consumers. However, somewhat absent from clinical education literature are practicable, low-cost classroom-based learning activities that can support development of such transferable competencies.

Our research aimed to address this gap by exploring three aspects of VTS implementation in our BPharm curriculum. Firstly, to evaluate student perceptions of the effect of VTS sessions on their skills and attitude development relating to providing inclusive person-centered care. Secondly, to examine the extent to which transfer of these skills to other settings, as reported by students, occurred since transfer of learning from academic to real-world settings is a challenging goal to realise..$^{29,30}$ Finally, this enquiry was important as curricula are crowded spaces ${ }^{31}$ and we needed to ensure that students were accepting of VTS and that the method was providing the intended experiential development and transfer of competencies.

\section{METHODS}

During Year 2 of the BPharm program, students participated in ten VTS sessions ( 8 - 18 students/session), over two semesters. The sessions were inserted into the final part of 2-hour pharmacy practice tutorials, covering topics such as communication and professionalism. The tutorials were streamlined to accommodate VTS. At the beginning and end of the year, students individually wrote about a creative work (the same visual image) using the required questions from the VTS methodology: 'What's going on in this image?', 'What do I see that makes me say that?' and 'What more can I find?' 24

Each approximately 30-minute session involved small group oral discussions using the same questions, where between one and three images (usually two) were discussed.

Sessions occurred in standard teaching spaces and used projected images chosen to engage students and explore aspects of inclusion. Adhering to the VTS method, presented images became deliberately more ambiguous, and therefore challenging to interpret, as the year progressed. To maintain engagement, part way through the series students could choose from several images presented to them. Following Housen's image selection method, over the multiple sessions, we moved from less-complex, image 1 July 7 (Frederick D. Jones, 1958) ${ }^{32}$ to more abstract, image 2 Roots (Frida Kahlo, 1943) ${ }^{33}$ and increasingly ambiguous images, image 3, Daughter (Gregory Crewdson, 2002) ${ }^{34}$, with the potential for multiple interpretations. Images of the artworks can be accessed through Google.com image searches.

To encourage transference of VTS ideas and skills the writing was purposefully linked to a 4-part 2,500 word assignment. This incorporated: pre/post VTS writing sessions, quality and interpretation comparisons of student's own work, anonymous peer-review using a web-based tool (each post submission reviewed by two peers), reflections on their learning through the VTS sessions and the potential impact of VTS on their future pharmacy practice. Images were also linked to other course activities relating to culture and communication.

\section{Study Design}

The evaluation used a cross-sectional study design. In November 2017, all members of two successive cohorts of students completing the VTS sessions were asked to complete a 38-item online reflective questionnaire.

Completion of the questionnaire addressed some of the course professional learning outcomes and the study aims. The two VTS facilitator research team members (TA clinical and professional skills module leader and LP program director) developed the questionnaire. The Qualtrics administered questionnaire comprised items requiring Likertscale, binary fixed choice and explanatory free-text responses. It collected high level demographic data, self-assessed skills development, self-reported transference of skills and student views on the acceptability and value of the sessions. Completing the questionnaire was compulsory as it was considered part of the reflective learning component of the program. However, allowing one's responses to be included in the research project was optional.

The study exclusion criterion was any student not participating in a year of VTS sessions and/or who had not agreed to participate in the study. To preserve student confidentiality the data were downloaded into a spreadsheet by a non-pharmacy research team member (JE). JE then separated out and de-identified the responses of those students agreeing to participate in the study, prior to TA and LP being given access to the data. All research participants were entered into a prize draw, managed by JE, to win one of two $\$ 50$ cafe vouchers. This research was approved by the University of Auckland Human Participants Ethics Committee on $14^{\text {th }}$ September 2017 reference 019176. 
This paper reports on findings related to inclusive practice, a short article relating to collaborative skills development arising from this study has already been published. ${ }^{35}$

\section{Data analysis}

Closed-question responses were analyzed in Excel to produce descriptive statistics. Open-text responses were categorized and quantified using an inductive approach and manifest content analysis. ${ }^{36,37}$ Open text responses were categorized by TA and LP separately before comparing and agreeing upon the final categories and themes. Exemplar quotes from the explanatory open-text responses were used to enrich and illustrate the quantitative findings.

\section{RESULTS}

All 174 students who had completed their second BPharm year in 2016 and 2017 were invited to participate. Ninety-eight (56\%) students consented to their responses being included in this study (25/76 from cohort one; $73 / 98$ from cohort two).

\section{Participation}

Seventy-four students (75.5\%) reported mainly listening in the VTS sessions, 38 (38.8\%) spoke most of the time and $35(35.7 \%)$ added to the ideas of others some of the time. Table 1 provides additional details regarding respondents' characteristics and actions during the VTS sessions.

\section{Skills development}

With respect to inclusive practice skills development, students were asked whether they believed that attending VTS sessions had improved specific components of their communication, cultural competence and critical thinking skills. Participants overwhelmingly agreed that they had, with the lowest level of agreement reported for an item being $74.5 \%$. Table 2 reports the frequency distribution for six questions, describing the student-perceived development of skills, competencies and abilities through participation in VTS sessions.

Additional professional skills believed to have been developed or improved through participation in the VTS sessions were explored through an open-text question. Responses were thematically analyzed and subsequently categorized into four broad skill-based themes of: person-centered communication, cultural safety, habits of mind, and personal and professional. Table 3 contains illustrative student quotes related to those themes.

\section{Transfer of learning}

With respect to learning transference, fifty-nine students $(60.2 \%)$ had thought about the VTS questions or used what they had learned in VTS sessions in settings outside of their BPharm clinical and professional skills classes. Open-text responses describing where these had been applied were categorized into 13 settings (Table 4). Forty-eight participants reported using VTS skills in other settings, the most frequent being everyday life $(\mathrm{n}=15)$. Forty-five (45.9\%) students had thought about the VTS skills or key questions during their placements or in other professional pharmacy practice settings, such as part-time pharmacy jobs.

\section{VTS in the curriculum}

Students were asked for their views on whether VTS sessions should remain part of the BPharm program. Eighty-four students agreed that they should, 9 were neutral and 5 disagreed. Themes arising from the reasons provided were developing communication skills, including the confidence to communicate, open-mindedness, critical thinking, and self-reflection. Table 5 contains the themes with illustrative quotes. Additionally, some respondents cited the open and accepting environment of the sessions; others wanted the sessions to remain as they were fun, enjoyable and/or interesting and some described their change in attitude towards the sessions as the year progressed. Eleven respondents believed there were too many VTS sessions in the year, 81 thought that 10 sessions were "about right" and 6 thought there were too few.

\section{DISCUSSION}

We adapted the Visual Thinking Strategy methodology for use with pharmacist trainees and the pharmacy contexts of New Zealand, and to align with the Competence Standards for the Pharmacy Profession in New Zealand. ${ }^{19}$ This study explored student perceptions of their skills development relating to person-centered care as a result of participation in a series of VTS activities, the transfer of this learning to other settings and student views on VTS and participating in the sessions. This study is framed around the self-evaluation of students of their VTS work.

Overall, the results indicate Visual Thinking Strategy sessions make a valuable addition to our pharmacy curriculum, offering opportunities for students to integrate learning and transfer skills, knowledge and attitudes both horizontally and vertically across the curriculum and into settings beyond academia.

Student perceptions of the effect of VTS session participation on their skills and attitude development were positive. Students generally believed the sessions had supported the development of all the skills/abilities surveyed, 
reporting a minimum level of agreement with improvement occurring of $74.5 \%$. Three areas were rated particularly strongly in respect to their: ability to consider different ideas (65.3\% strongly agreed), critical thinking skills (40.8\% strongly agreed) and active listening skills (40.8\% strongly agreed) development.

Advancement of these competencies through VTS has also been reported by others using student selfreports. ${ }^{28,38,39}$ It should be noted that a recent narrative review concluded that, apart from clinical observation skills, evidence for visual image instruction in developing other skills during medical education is poor. ${ }^{40}$ However, unlike these other single-session interventions, our findings arise from participation in multiple VTS sessions and related activities across an entire academic year. This was deliberate, as Housen's original VTS studies revealed that repeated sessions were optimal for embedding skills and realizing transference of learning to other situations. ${ }^{23,41}$ With minimal space available in the curriculum, a series of VTS sessions was incorporated within existing Year 2 foundational skills teaching sessions. Naghshineh et al ${ }^{42}$ noted a skill building VTS session "dose" effect with medical students; Poirier et al recently reported that participation in a series of 15-minute VTS sessions resulted in more observations being made about images by pharmacy students. ${ }^{43}$

A focus on skills/attitudes developed in these sessions, could be considered as fostering the 'habits of mind' that Costa and Kallick note should be "performed automatically, spontaneously, and without prompting". ${ }^{44}$ Achieving this requires regular practice and the beneficial effect of participating in numerous sessions was noted by some of our students who recognized their own initial resistance to the sessions, and their later transformed views, attitudes and skills development over time.

A recent review by Mukunda recommends that visual image evaluations should incorporate more rigour. ${ }^{40}$ Although not presented as data in this study (due to ethical constraints), respondent perceptions of their skills growth over the year due to VTS in this study are consistent with the changes reflected in the students' written VTS assignment submissions, which are assessed against a validated VTS assessment rubric. The rubric examines elements such as students' observations, interpretations, evidence provision and revised opinions.

Participating in VTS sessions appears to address the affective domain of learning which is recognized globally for its importance in supporting students to manage the emotional contexts and dissonance of interacting with people with diverse views and experiences. ${ }^{22}$ Similarly, Frei et al used art observation and interpretation with nursing students to develop nuanced understanding of communication, power in relationships, and empathy. ${ }^{45}$

Additionally, VTS allows the facilitator to model inclusive practices and for participants to experience being listened to, having their views validated and being asked to justify their viewpoint in an open and non-judgmental manner. ${ }^{39}$ The consistent process and safe environment encourages students to gain confidence to express their ideas and to actively, and respectfully, disagree with others. ${ }^{46}$

Another strength of the VTS method is the flexibility afforded by image selection. We deliberately selected images to challenge students and tap into the affective domain of learning to align with our own curricular goals and context. However, image selection can be considered as a tool to focus student learning on other desired learning domains and goals. ${ }^{28}$

We assert the retention, habitual use and transference of the skills and attitudes we surveyed is crucial for the development of inclusive health practitioners. Our findings suggest that the VTS-acquired learning is transferred to other settings. We believe that modelling being reflective practitioners, and the habitual use of the VTS 3-question facilitation structure, aided students in their transference of VTS skills and attitudes to other settings. Students participating in this study agreed that their VTS learning had been used in other areas both in pharmacy and nonpharmacy settings. Fellow students could also be considered colleagues and VTS has been described as a model of engaged discussion where participation is expected. ${ }^{46}$ To increase learning transference, Caffarella highlights the significance of active learning techniques that include application of knowledge and critical reflection opportunities embedded within this new learning. ${ }^{47}$ In addition to the active learning that occurs during VTS sessions, transfer of VTS learning was also encouraged through the 4-part VTS assignment that required students to reflect on and document: the writing of others about an image, changes in their own interpretations of an image, and where their developing skills will be useful in future pharmacy practice. Completing the questionnaire served as a reflection point, hence it was mandatory.

Purposeful reflection is a tool for gaining self-knowledge and insight. ${ }^{48}$ Mezirow's assertion that critical selfreflection can lead to transformational learning ${ }^{49}$ supports our own observations and the central role of self-reflection in professional development is further documented elsewhere in clinical education literature. ${ }^{12-14,22,29,50}$

Students were overwhelmingly positive about the acceptability of participating in the series of art-based VTS sessions with $86 \%$ believing that it should remain in the curriculum despite almost a quarter of study participants indicating no prior interest in art (not further defined) and half self-reporting no art knowledge. Whilst some students appreciated the skills-building aspect of the sessions, others' reasons included enjoyment, interest and a break from a "science-only" focus that the sessions provided. Poirier has likewise reported pharmacy student enjoyment of VTS sessions. ${ }^{43}$

\section{Limitations}


The main limitation of this study is that the findings arise from student self-reported perceptions of VTS sessions. Additionally, for ethical reasons no control group was used. Data were gathered soon after the completion of the session series for some participants and 12 months post completion for others. Whilst this resulted in a lower response rate, one could argue that collecting data 12 months post participation gives time for VTS skills to be applied and the significance or insignificance of VTS to be recognized. The response rate was $56 \%$ therefore responder bias, with or without social desirability bias, could have occurred where only students with favorable views consented to participate in the study, despite survey responses being de-identified prior to analysis. It is also possible that students misattributed their skills growth to VTS when it arose from increasing maturity, other teaching activities and/or experiences or that their skills growth resulting from VTS participation was unrecognized.

\section{CONCLUSION}

This study adds to the body of literature examining practical methods to develop person-centered practices and transferable competencies in pharmacy students through structuring of divergent, discussion-based reflective activities in class. Incorporating multiple VTS sessions into Year 2 of the BPharm program appears to have been a valuable addition to the curriculum. The sessions are acceptable to students and seem to support the development of key skills and attitudes relating to providing inclusive person-centered care that incorporates principles of cultural safety, critical thinking and professional skills such as communication and self-reflection. VTS also offers opportunities for students to integrate learning from other areas of the curriculum and students report transference of attitudes and skills to other areas of the curriculum, practice and their lives. Future research will aim to provide evidence to support our hypothesis that development of particular skills and attitudes, with a focus on affective learning, can be supported through judicious image selection and the priming of students by articulating the overall purpose of VTS in the curriculum and the focus of each session.

\section{ACKNOWLEDGMENTS}

We are grateful to all the students who gave permission for their information and views to be used to evaluate the implementation of VTS in the BPharm program. School of Pharmacy teaching funds provided the café vouchers for the prize draw.

\section{REFERENCES}

1. Ministry of Health. Achieving Equity. Ministry of Health. Accessed 22nd February 2021, 2020. https://www.health.govt.nz/about-ministry/what-we-do/work-programme-2019-20/achieving-equity

2. National Centre for Chronic Disease Prevention and Health Promotion. Health Equity. https://www.cdc.gov/chronicdisease/healthequity/index.htm

3. Miller A, Grohe M, Khoshbin S, Katz JT. From the galleries to the clinic: applying art museum lessons to patient care. J Med Humanit. Dec 2013;34(4):433-8. doi:https://dx.doi.org/10.1007/s10912-013-9250-8

4. Munro A, Boyce T, Marmot M. Sustainable health equity: achieving a net-zero UK. The Lancet. 2020;4(12):E551-E553. doi:https://doi.org/10.1016/S2542-5196(20)30270-9

5. Public Health Agency of Canada. Key Health Inequalities in Canada A National Portrait. 2018:437. https://www.canada.ca/content/dam/phac-aspc/documents/services/publications/science-research/keyhealth-inequalities-canada-national-portrait-executive-summary/hir-full-report-eng.pdf

6. Health and Disability Commissioner. Code of Health and Disability Services Consumers' Rights Regulations 1996. 1996.

7. Health and Disability System Review. Health and Disability System Review Health and Disability System Review executive overview. 2020:36. https://systemreview.health.govt.nz/assets/Uploads/hdsr/healthdisability-system-review-final-report-executive-overview.pdf

8. Richardson F. An introduction to inclusive practice. In: Davis J, Birks M, Chapman Y, eds. Inclusive Practice for Health Professionals. Oxford University Press; 2015:2-22:chap 1.

9. Smits K. Multiculturalism, Biculturalism, and National Identity in Aotearoa/New Zealand. In: Ashcroft R, Bevir M, eds. Multiculturalism in the British Commonwealth: Comparative Perspectives on Theory and Practice. University of California Press; 2019:104-124.

10. Ramsden I, Spoonley I. The cultural safety debate in nursing education in Aotearoa. New Zealand Annual Review of Education. 1993;3:161-173.

11. Curtis E, Jones R, Tipene-Leach D, et al. Why cultural safety rather than cultural competency is required to achieve health equity: a literature review and recommended definition. International Journal for Equity in Health. 2019;18doi:10.1186/s12939-019-1082-3

12. Haack S. Engaging pharmacy students with diverse patient populations to improve cultural competence. Am J Pharm Educ. 2008;72(5):Article 124. doi:10.5688/aj7205124

13. Driscoll J. Practicing Clinical Supervision: A Reflective Approach for Health care Professionals $2 n d$ ed. Balliere Tindall Elsevier; 2007. 
14. Schön D. The Reflective Practitioner: How professionals think in action. Temple Smith; 1983.

15. Zweber A. Cultural Competence in Pharmacy Practice. Am J Pharm Educ. 2002;66:172-176. doi:aj660214.pdf

16. Poirier T, Butler L, Devraj R, Gupchup G, Santanello C, Lynch J. A cultural competency course for pharmacy students. Am J Pharm Educ. 2009;73(5):81. doi:10.5688/aj730581

17. Vyas D, Caligiuri F. Reinforcing cultural competency concepts during introductory pharmacy practice experiences. Am J Pharm Educ. 2010;74(7):129. doi:10.5688/aj7407129

18. Pharmacy Council of New Zealand. Statement on cultural competence 2011:6. https://www.pharmacycouncil.org.nz/dnn_uploads/Documents/standardsguidelines/Cultural\%20Competan ce\%20statement\%202010-\%20web.pdf?ver=2017-02-20-105424-113

19. Pharmacy Council of New Zealand. Competence Standards for the Pharmacy Profession. 2015:40. https://enhance2.psnz.org.nz/assets/downloads/group_three/reflection/Standards_2015_FINAL.pdf

20. Aspden T, Butler R, Heinrich F, Harwood M, Sheridan J. Identifying key elements of cultural competence to incorporate into a New Zealand undergraduate pharmacy curriculum. Pharmacy Education. 2017;17(1):43-54.

21. Krathwohl D, Bloom B, Masia B. Taxonomy of Educational Objectives: The Classification of Educational Goals: Handbook II Affective Domain. David McKay Co. Inc; 1973.

22. Muzyk A, Lentz K, Green C, Fuller S, May B, Roukema L. Emphasizing Bloom's Affective Domain to Reduce Pharmacy Students' Stigmatizing Attitudes Am J Pharm Educ. 2017;81(2):Article 35. doi:10.5688/ajpe81235

23. Housen A. Aesthetic thought, critical thinking and transfer. Arts Learning J. 2002;18(1)

24. Yenawine P. Visual Thinking Strategies: Using art to deepen learning across school disciplines. Harvard Education Press; 2013.

25. Piaget J. The Psychology of Intelligence. Routledge; 1950.

26. Bruner J. Toward a theory of instruction. The Harvard University Press; 1966.

27. Klugman CM, Beckmann-Mendez D. One thousand words: evaluating an interdisciplinary art education program. J Nurs Educ. Apr 2015;54(4):220-3. doi:https://dx.doi.org/10.3928/01484834-20150318-06

28. Reilly JM, Ring J, Duke L. Visual thinking strategies: a new role for art in medical education. Fam Med. Apr 2005;37(4):250-2.

29. Caffarella R, Barnett B. Characteristics of Adult Learners and Foundations of Experiential Learning. New Directions for Adult and Continuing Education. 1994;62:29-42.

30. Bernander R. A Literature Summary for Research on the Transfer of Learning. 2018. http://www.oecd.org/education/2030-project/about/documents

31. Harden RM. Ten questions to ask when planning a course or curriculum. Medical Education. 1986;20:356365.

32. Jones FD. July 7. 1958.

33. Kahlo F. Roots. 1943.

34. Crewdson G. Daughter. in Twilight: Photographs by Gregory Crewdson: Abrams; 2002.

35. Aspden T, Wearn A, Petersen L. Skills by stealth: Developing pharmacist competencies using art. Medical Education. 2020;54(5):442-443. doi:10.1111/medu.14098

36. Bengtsson M. How to plan and perform a qualitative study using content analysis. NursingPlus Open. 2016;2:8-14. doi:10.1016/j.npls.2016.01.001

37. Graneheim UH, Lundman B. Qualitative content analysis in nursing research: concepts, procedures and measures to achieve trustworthiness. Nurse Educ Today. 2004;24:105-112.

38. Bentwich ME, Gilbey P. More than visual literacy: art and the enhancement of tolerance for ambiguity and empathy. BMC Med Educ. Nov 10 2017;17(1):200. doi:https://dx.doi.org/10.1186/s12909-017-1028-7

39. Moorman M, Hensel D. Using Visual Thinking Strategies in Nursing Education. Nurse Educator. Jan-Feb 2016;41(1):5-6. doi:https://dx.doi.org/10.1097/NNE.0000000000000185

40. Mukunda N, Moghbeli N, Rizzo A, Niepold S, Bassett B, DeLisser HM. Visual art instruction in medical education: a narrative review. Review. Med. Dec 2019;24(1):1558657. doi:https://dx.doi.org/10.1080/10872981.2018.1558657

41. Housen A. Methods for Assessing Transfer from an Art-Viewing Program. presented at: Annual Meeting of the American Educational Research Association 2001; Seattle, USA.

42. Naghshineh S, Hafler JP, Miller AR, et al. Formal art observation training improves medical students' visual diagnostic skills. Journal of General Internal Medicine. 2008 23:991-997.

43. Poirier TI, Newman K, Ronald K. An Exploratory Study Using Visual Thinking Strategies to Improve Undergraduate Students' Observational Skills. Am J Pharm Educ. 2020;84(4):Article 7600.

doi:https://dx.doi.org/10.5688/ajpe7600 
44. Costa AL, Kallick B. Learning and leading with habits of mind: 16 essential characteristics for success. Association for Supervision and Curriculum Development; 2008.

45. Frei J, Alvarez S, Alexander M. Ways of Seeing: Using the Visual Arts in Nursing Education. J Nurs Educ. 2010;49(12):672-676.

46. Nelson A. Visual Thinking Strategies from the Museum to the Library: Using VTS and Art in Information Literacy Instruction. Art Documentation: Journal of the Art Libraries Society of North America. 2017;36(2):281-292.

47. Caffarella R. Devising Transfer-of-Learning Plans. In: Caffarella R, ed. Planning Programs for Adult Learners: A Practical Guide for Educators, Trainers, and Staff Developers (2nd ed). Jossey-Bass; 2002:203-223:chap 10.

48. Palmer PJ. The courage to teach: Exploring the inner landscape of a teacher's life. Jossey-Bass; 2007.

49. Mezirow J. Fostering critical thinking in adulthood: A guide to transformative and emancipator learning. Jossey-Bass; 1990.

50. Boud D, Keogh R, Walker D. Reflection: Turning Experience into Learning. Kogan Page; 1985.

Table 1. Survey Respondent Characteristics and Behaviors During VTS Sessions (N=98)

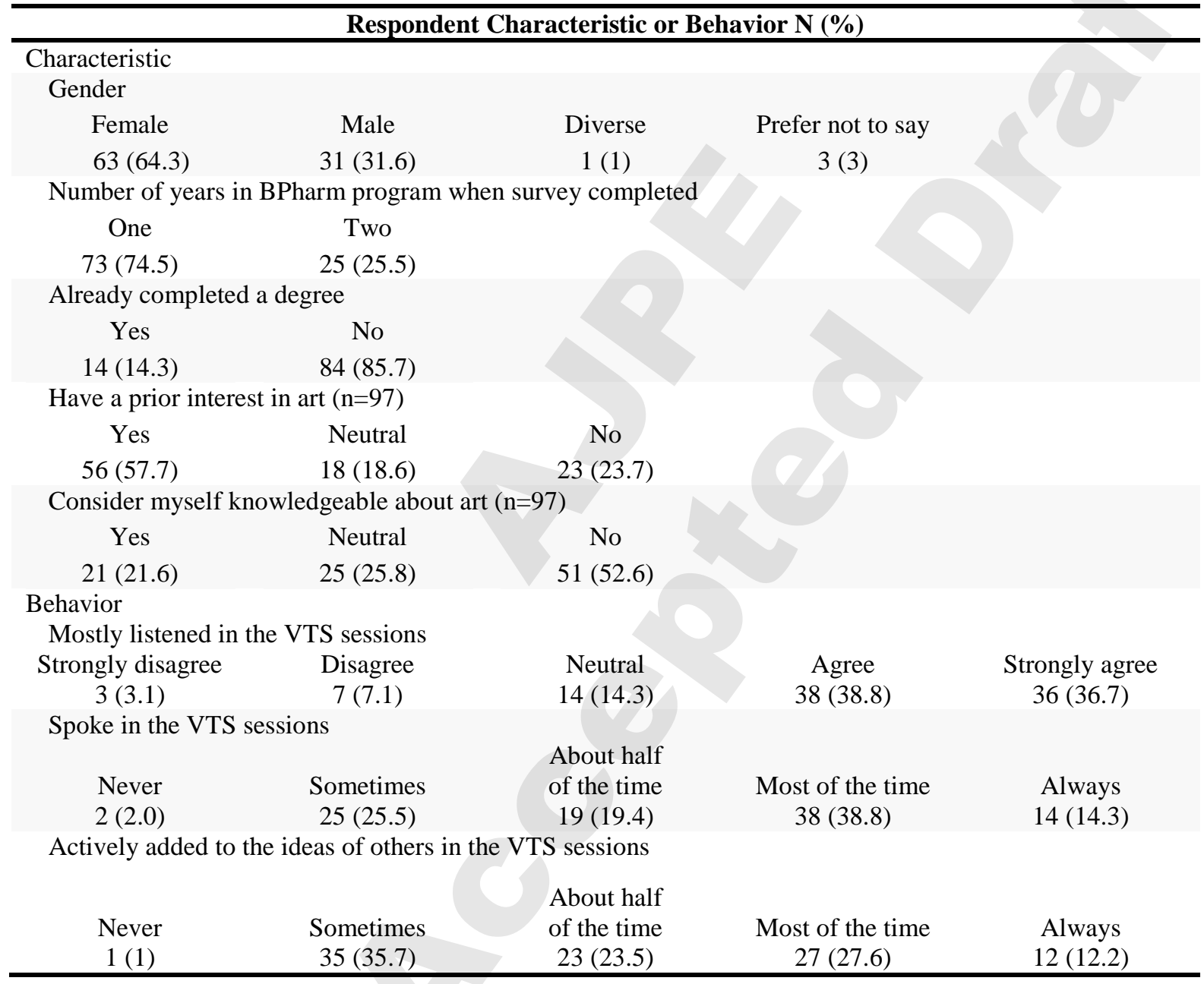


Table 2. The Perceived Effect of Participation in Visual Thinking Strategy (VTS) Sessions on BPharm Students' Skills, Competency and Attitude Development $(\mathrm{N}=98)$

\section{Participant response N $(\%)$}

\begin{tabular}{|c|c|c|c|c|c|}
\hline $\begin{array}{l}\text { My [skill/competence/ability to] } \\
\text { improved through attending } \\
\text { the series of VTS sessions }\end{array}$ & $\begin{array}{l}\text { Strongly } \\
\text { agree }\end{array}$ & Agree & $\begin{array}{l}\text { Neither } \\
\text { agree nor } \\
\text { disagree }\end{array}$ & Disagree & $\begin{array}{l}\text { Strongly } \\
\text { disagree }\end{array}$ \\
\hline Active listening & $40(40.8)$ & $41(41.8)$ & $13(13.3)$ & $4(4.1)$ & $0(0)$ \\
\hline Concise oral summary & $26(26.5)$ & $64(65.3)$ & $6(6.1)$ & $2(2)$ & $0(0)$ \\
\hline Critical thinking & $40(40.8)$ & $47(48)$ & $9(9.2)$ & $2(2)$ & $0(0)$ \\
\hline Cultural competencies & $31(31.6)$ & $42(42.9)$ & $21(21.4)$ & $3(3)$ & $1(1)$ \\
\hline $\begin{array}{l}\text { Meet the needs of diverse } \\
\text { health consumers }\end{array}$ & $30(30.6)$ & $44(44.9)$ & $20(20.4)$ & $3(3)$ & $1(1)$ \\
\hline $\begin{array}{l}\text { Consider different ideas and } \\
\text { contrary opinions with a more } \\
\text { open attitude }\end{array}$ & $64(65.3)$ & $28(28.6)$ & $5(5.1)$ & $1(1)$ & $0(0)$ \\
\hline
\end{tabular}

Table 3. Themes and Illustrative Participant Quotes Relating to Additional Professional Skills Students Perceived They Gained Through Participation in Visual Thinking Strategy (VTS) Sessions

\begin{tabular}{ll}
\hline Theme & Participant Quotes \\
\hline Person-centered & "Helped to improve skills in conveying empathy" (P9 Year 2) \\
Communication & "Appreciating different perspectives/ideas, and then integrating them into a \\
& narrative/summary; eg, collaborating with a patient to develop a care plan." (P17 \\
& Year 2) \\
& "Understanding the patient's perspective, but also observing them more \\
holistically. Additionally to not make assumptions about people." (P67 Year 3) & "I have better insight into how the patient's background might affect their beliefs \\
& around medication." (P2 Year 2) \\
"Being able to take into account the perspective and opinions of others, and to not & just make decisions and conclusions based on my own understanding." (P8 Year 3) \\
"Being able to interpret a situation in different ways and looking at it from other \\
people's perspective" (P63 Year 3)
\end{tabular}

Habits of Mind "Taking time to consider a situation in all aspects before acting. Looking for more in a situation even when you think you have covered all aspects." (P23 Year 3)

"Understanding the 'why' part behind things, and not just coming to a conclusion based on what is placed right in front of me." (P48 Year 2)

"To accept ambiguity and the diversity of ideas" (P81 Year 2)

Personal and

Professional

"Building on each other's ideas. I believe this will be an important skill in the future when negotiating with patients and other health professionals.” (P27 Year 2)

"Professionalism - I have developed the ability to explain things in a more formal and appropriate manner. Choosing the right words and focusing carefully on sentence structure, so as not to convey messages inappropriately is another skill I have developed over the past Learn To See sessions. " (P28 Year 2) 
Table 4. Categorized Free-text Responses Describing Self-reported Transfer of Learning from Visual Thinking Strategies (VTS) Sessions to Other Settings ( $N=59$ students providing 63 settings)

\begin{tabular}{lc}
\hline Setting & $\mathbf{N}(\boldsymbol{\%})$ \\
\hline Everyday life & $15(25.4)$ \\
Pharmacy placements & $9(15.3)$ \\
Other university workshops, lectures and/or assignments & $6(10.2)$ \\
With family / at home & $6(10.2)$ \\
Pharmacy job & $5(8.5)$ \\
With people & $5(8.5)$ \\
With peers / friends & $4(6.8)$ \\
During retail work / part-time job & $3(5.1)$ \\
Teamwork settings / during group activities & $3(5.1)$ \\
Art galleries or when viewing art & $2(3.4)$ \\
General health care settings & $2(3.4)$ \\
When watching the news, advertising or reading articles & $2(3.4)$ \\
During recreation time when playing strategy games & $1(1.7)$ \\
Total & $63\left(106.8^{a}\right)$ \\
\hline
\end{tabular}

${ }^{a}$ Responses add up to more than $100 \%$ as respondents could choose more than one setting and rounding

Table 5. Student Respondents' Views on Whether the Visual Thinking Strategies (VTS) Intervention Should Remain in the BPharm Program and Reasons Given for Those Views (N=98)

\begin{tabular}{|c|c|c|c|c|c|}
\hline \multicolumn{6}{|l|}{ Opinions expressed } \\
\hline $\begin{array}{l}\text { VTS should remain } \\
\text { part of the BPharm } \\
\text { program }\end{array}$ & $\begin{array}{l}\text { Strongly } \\
\text { disagree } \\
\mathrm{N}(\%) \\
2(2)\end{array}$ & $\begin{array}{l}\text { Somewhat } \\
\text { disagree } \\
\mathrm{N}(\%) \\
3(3)\end{array}$ & $\begin{array}{l}\text { Neither agree } \\
\text { nor disagree } \\
\quad \mathrm{N}(\%) \\
9(9.2)\end{array}$ & $\begin{array}{l}\text { Somewhat } \\
\text { agree } \\
\mathrm{N}(\%) \\
39(39.8)\end{array}$ & $\begin{array}{l}\text { Strongly agree } \\
\quad \mathrm{N}(\%) \\
45(45.9)\end{array}$ \\
\hline \multicolumn{6}{|l|}{ Reasons } \\
\hline Theme & \multicolumn{5}{|c|}{ Participant Quotes } \\
\hline $\begin{array}{l}\text { Development of } \\
\text { more open-minded } \\
\text { attitudes to different } \\
\text { perspectives and }\end{array}$ & \multicolumn{5}{|c|}{$\begin{array}{l}\text { "In the first semester I hated learn to see and thought that what people were } \\
\text { saying was ridiculous. I now realise that everyone does have a valid point, and } \\
\text { that there is a purpose in these exercises. Generally, I just really enjoy these } \\
\text { sessions." (P88 Year 2) }\end{array}$} \\
\hline & \multicolumn{5}{|c|}{$\begin{array}{l}\text { "It's a useful tool that helps students become more open-minded about other } \\
\text { people's opinions and being able to confidently voice their own perspectives } \\
\text { because of their ability to give evidence." (P97 Year 3) }\end{array}$} \\
\hline $\begin{array}{l}\text { Development of } \\
\text { critical thinking } \\
\text { skills through } \\
\text { facilitated group } \\
\text { discussion }\end{array}$ & \multicolumn{5}{|c|}{$\begin{array}{l}\text { "Helps to ease into the profession and develop critical thinking skills through a } \\
\text { fun and interactive process." (P38 Year 2) }\end{array}$} \\
\hline
\end{tabular}


"They're great for making students think in unconventional ways and allowing them to express themselves, which is hard to do in a clinical program like pharmacy. It's a kind of interaction/discussion that we don't really get to experience, and I think that it is invaluable to our learning. It also facilitates the development of our critical thinking skills, which will form a major part of our practice as future pharmacists and they're really fun!" (P88 Year 2)

Development of communication skills and confidence to express own ideas

Development of personal selfreflection skills
"Becoming more involved and participating in group discussions, which was something I did less of previously, due to the open environment." (P10 Year 2)

"At first, I did not understand why we had to do them [VTS sessions] as I couldn't see how it related to the programme but over time, I saw my own communication skills develop and I think it's useful to be able to have someone relay back the information you've said as you're never sure if you've explained it clearly to someone." (P19 Year 2)

"It is actually a very interesting programme and is very different from the lectures and workshops that we have. It encourages us to voice our opinions in a constructive manner." (P20 Year 2)

“...learn to see sessions also encouraged me to speak up and be bold" (P96 Year 3)

"You don't realise it helps until you reflect. It may seem pointless and weird at the beginning, but once you see the true purpose and realise how it has changed or improved or added to your skills repertoire then you will really start to enjoy the sessions." (P7 Year 2)

"... these workshops were a first prompt for me to self-reflect at a university level and this has facilitated better self-reflection ever since." (P70 Year 3) 